\title{
Por um ensino de língua portuguesa \\ a sociolinguisticamente \\ orientado
}

OPEN ACCESS

EDITADO POR

Raquel Freitag (PPGL/UFS)

REVISADO POR

Isabel de Oliveira e Silva

Monguilhott

SOBRE OS AUTORES

Victor Renê Andrade Souza

Contribuiu com Vitória Laís

Santos Silva e Lucas Santos

Silva. Papéis: conceptualização,

supervisão, escrita - análise e

edição.

Vitória Laîs Santos Silva

Contribuiu com Victor Renê Andrade Souza e Lucas Santos Silva. Papéis: conceptualização,

escrita - rascunho original.

Lucas Santos Silva

Contribuiu com Victor Renê Andrade Souza e Vitória Laís

Santos Silva. Papéis: investigação, escrita - análise e edição.

DATAS

Recebido: 15/05/2020

Aceito: 20/05/2020

Publicado: 27/06/2020

COMO CITAR

Souza, V. R. A; Silva, V. L. S.;

Silva, L. S. (2020).

Por um ensino de língua

portuguesa

sociolinguisticamente

orientado. Revista da Abralin, v.

19, n. 2, p. 1-5, 2020.

\author{
Victor Renê Andrade SOUZA (D) \\ Universidade Federal de Sergipe (UFS) \\ Vitória Laís Santos SILVA (D) \\ Universidade Federal de Sergipe (UFS) \\ Lucas Santos SILVA (D) \\ Universidade Federal de Sergipe (UFS)
}

RESUMO

Este texto apresenta uma resenha crítica e colaborativa da conferência "Bases para uma pedagogia da variação linguística" proferida por Carlos Alberto Faraco (UFPR) e mediada por Raquel Meister Ko. Freitag (UFS) no evento Abralin ao Vivo - Linguists Online, organizado pela Associação Brasileira de Linguística (Abralin). Faraco advogou acerca das bases para uma pedagogia da variação linguística (FARACO, 2008; ZILLES; FARACO, 2015). O conferencista discutiu conceitos sociolinguísticos basilares, como a noção de normas linguísticas; abordou os princípios e objetivos da proposta pedagógica, apontando as dificuldades da implementação no ensino de língua portuguesa na educação básica; e destacou os avanços nas propostas pedagógicas baseadas numa pedagogia da variação linguística.

\section{ABSTRACT}

This text presents a critical and collaborative review of the lecture Bases towards a pedagody of linguistic variation given by the linguist Carlos Alberto Faraco (UFPR) and mediated by Professor Raquel Meister Ko. Freitag (UFS) at the ABRALIN AO VIVO - LINGUISTS ONLINE, which was held by the Brazilian Linguistics Association, Abralin. Faraco argued for the bases towards a 


\section{REVISTA DA ABRALIN}

pedagogy of linguistic variation (FARACO, 2008; ZILLES; FARACO, 2015). The lecturer discussed basic sociolinguistic concepts as the notion of linguistic norms. He approached the principles and objectives of this pedagogic proposal, pointing out the difficulties of implementing it in the teaching of Portuguese language at elementary education. He also highlighted the advances in the pedagogic proposals based on a pedagogy of linguistic variation.

\section{PALAVRAS-CHAVE}

Variação linguística. Pedagogia da variação linguística. Carlos Alberto Faraco.

\section{KEYWORDS}

Linguistic variation. Pedagogy of linguistic variation. Carlos Alberto Faraco.

Estudos acerca da variação linguística não são incipientes no Brasil e uma proposta de ensino voltada à diversidade linguística não é novidade. A Sociolinguística brasileira tem um amplo conjunto de trabalhos descritivos que sistematizam e explicam a variação (cf. PAIVA; SCHERRE, 1999; SCHERRE, 2012; ABRAÇADO; MARTINS, 2015; FREITAG, 2016). A diversidade linguística já figura nos documentos oficias das políticas públicas educacionais (cf. FREITAG, 2015; ANDRADE; FREITAG, 2016; CONCEIÇÃO; PEREIRA, 2018). Entretanto, o grande gargalo é fazer com que a compreensão da variação linguística extrapole os meios acadêmicos e chegue efetivamente às salas de aula de língua portuguesa. Como alternativa a esse desafio, o professor Carlos Alberto Faraco propõe as bases para uma pedagogia da variação linguística (FARACO, 2008; ZILLES; FARACO, 2015), tema de sua conferência, ocorrida no dia 08 de maio de 2020 no evento Abralin ao Vivo - Linguists Online, organizado pela Associação Brasileira de Linguística.

A pedagogia da variação linguística defendida por Faraco se aproxima da Sociolinguística Educacional, proposta pela professora Stella Maris Bortoni-Ricardo (2004). É a Sociolinguística a serviço da educação, tal qual desenvolvida pioneiramente por Labov (1972), na obra Language in the Inner City: Studies in the Black English Vernacular. Para Faraco, significa pensar em um ensino de português sociolinguisticamente bem informado em bases empíricas, o que pressupõe uma abordagem não "folclorizada" e "cosmética" da variação.

Não existem línguas fora das sociedades humanas. A diversidade linguística é reflexo da organização social. Faraco argumenta que entender a heterogeneidade da língua é entender a sociedade em que vivemos, sua história, sua cara socioeconômica e cultural, como destaca Dante Lucchesi (2015), no livro Língua e Sociedades Partidas: a polarização sociolinguística no Brasil. Somente a partir desta compreensão é possível desenvolver práticas pedagógicas que conquistem os alunos e oriente- 


\section{REVISTA DA ABRALIN}

os a uma atitude de respeito linguístico, na medida em que se apropriem da história social, da miscigenação dos povos e do impacto desses fatores na estrutura linguística.

Nesse sentido, consoante a Faraco, cabe aos professores de língua portuguesa desenvolver uma pedagogia da variação linguística, integrada às demais dimensões do ensino de língua, com vistas a três grandes objetivos: i) conhecer e entender a variação linguística; ii) entender e respeitar a variação linguística; e iii) entender e transitar com segurança pelo universo da variação linguística.

Entretanto, Faraco reconhece que percorrer este caminho não é fácil e aponta os desafios imbricados na consecução desses objetivos. O conhecimento consistente da variação linguística é pouco disseminado entre professores de língua portuguesa e entre alunos dos cursos de Letras, já que eles muitas vezes saem sem entender suficientemente sobre variação linguística e sem sequer superar criticamente os estigmas sociais, contrariando o terceiro dos objetivos. Tendo em vista que o evento Abralin ao Vivo - Linguists Online tem um público-alvo especializado, perguntas feitas no chat durante a transmissão ao vivo da conferência do professor Faraco sinalizam falhas na formação inicial de professores para o ensino de língua materna: “Quando um adulto fala 'eu ouvo' podemos considerar como variação linguística?"; "Você poderia explicar se, um adulto que emprega de maneira errada uma palavra (no âmbito gramatical, semântico), mesmo tendo acesso às normas gramaticais, está cometendo desvio ou variação?"; "Quando o aluno fala errado na sala de aula e o professor imediatamente o corrige é correto?".

Na mesma direção, não é fácil enfrentar as representações do senso-comum acerca das normas linguísticas, baseadas numa prescrição de gramáticas tradicionais. Faraco traz ao debate a celeuma do livro didático Para uma Vida Melhor que abordava variação linguística e foi alvo de críticas pelos principais meios de comunicação no Brasil, levantando em todas as esferas um intenso debate acerca do ensino de língua portuguesa (LUCCHESI, 2011). No episódio, Faraco destaca que à época um renomado gramático afirmou que a variação linguística deveria ficar restrita ao universo acadêmico, pois a única função da escola seria ensinar a norma padrão. Essa afirmação é mais uma amostra do desafio que envolve a aplicação da pedagogia da variação linguística.

Faraco critica também o forte imaginário social que estigmatiza parte das variedades linguísticas e afirma que a nossa sociedade é extremamente polarizada. Por isso, é provável que a pedagogia da variação linguística seja recusada nas escolas, pois os dirigentes, professores, pais e até mesmo os alunos estão imersos no imaginário social que demoniza a variação, seja ela linguística ou social. Esse imaginário autoritário defende que a língua é homogênea e que todos devem falar igual, transformando a diferença linguística em marca de inferioridade. Assim, assumir uma pedagogia da variação linguística requer um compromisso político, um ativismo sociolinguístico pela construção de uma sociedade justa, democrática e pluralista.

Nenhuma variedade é linguisticamente superior à outra, mas, apesar de não haver hierarquização dessas variedades baseada em critérios linguísticos, há hierarquização construída histórica e socialmente. Perceber esse constructo histórico-social é uma revolução conceitual e valorativa que nos permite questionar e desconstruir essa hierarquização. E é no interior desse quadro que Faraco defende ser possível entender a existência da norma de referência pertinente a certas situações linguísticas e 


\section{REVISTA DA ABRALIN}

ser importante conhecer essa norma como parte do domínio das respectivas práticas e tradições em que ela é pertinente. Faraco argumenta que não existe conflito em adotar uma pedagogia da variação linguística e o ensino de uma norma. O professor propõe, dentro da própria pedagogia da variação linguística, o desenvolvimento de uma pedagogia da norma de referência - termo adotado em alternativa à expressão norma culta - a fim de escancarar que não há negação da norma de referência. Assim, os defensores da pedagogia da variação linguística devem garantir que os alunos, além de compreenderem e respeitarem a variedade linguística, tenham acesso à norma de referência, conhecendo e dominando suas funcionalidades e características, sobretudo no que tange à escrita monitorada.

Entretanto, o linguista argumenta que essa norma de referência deveria se relacionar com o que ele chama de português standard falado, isto é, com a norma culta falada. Faraco salienta a confusão terminológica e conceitual que afeta a questão da norma de referência, assumindo que é tarefa urgente das universidades destrinchar essa confusão. Além disso, sinaliza que não foi construído até hoje um consenso sobre a norma de referência, fato que deixa os professores sem um norte seguro de qual normatização seguir e ensinar. Para o linguista, as contradições entre os instrumentos normativos são pouco percebidas pelos professores, mídia e público em geral, e essa falta de um direcionamento normativo relativamente consensual acaba por dar espaço ao que ele chama de norma curta, que é um discurso autoritário, dogmático, inflexível e sem fundamento empírico sobre a língua, resultando em rótulos de avaliação social como "essa palavra não existe na língua X", "é errado falar assim". É preciso construir um consenso com base em um estudo empiricamente consistente e desenvolver um conceito flexível de norma de referência, o que significa fazê-la emergir das práticas do português brasileiro standard.

Voltando aos desafios do ensino de língua portuguesa, Faraco diz que a escola deve garantir o domínio e o acesso ao português brasileiro standard falado e, dentro desse processo, à variedade normatizada, ou em outros termos à modalidade formal escrita do português brasileiro contemporâneo. Assim, não há como trabalhar com a variedade do português brasileiro standard sem situá-la no quadro amplo da variação linguística.

Em suas palavras finais, o linguista destaca os avanços no que tange às práticas pedagógicas baseadas na pedagogia da variação linguística, na figura das propostas da professora Silvia Rodrigues Vieira (UFRJ) (cf. VIEIRA, 2018), que publicou juntamente com Monique Débora Alves de Oliveira Lima o ebook Variação, gêneros textuais e ensino de português: da norma culta à norma padrão (VIEIRA; LIMA, 2019), obra que demonstra como é fundamental trabalhar a variação linguística nos contínuos propostos por Bortoni-Ricardo (2004), tendo os diferentes gêneros textuais como referência. Carlos Alberto Faraco encerra sua potente fala afirmando que a tradição escolar opera com rigidez e se sustenta numa cultura do erro e que o horizonte que estamos a desbravar é o da flexibilidade e o da cultura da adequação. 


\title{
REVISTA DA ABRALIN
}

\author{
REFERÊNCIAS
}

ABRAÇADO, J.; MARTINS, M. A. (Ed.). Mapeamento sociolinguístico do português brasileiro. Editora Contexto, 2015.

ANDRADE, S. R. de J.; FREITAG, R. M. K. A evolução do tratamento da variação linguística no Enem. Signum:

Estudos da Linguagem, v. 19, n. 1, p. 293-320, 2016.

BASES para uma pedagogia da variação linguística. Conferência apresentada por Carlos Alberto Faraco [s.l., s.n.], 2020. 1 vídeo (1h 9 min 15s). Publicado pelo canal da Associação Brasileira de Linguística. Disponível em: https://www.youtube.com/watch?v=3kS-RHie0Zw\&feature=emb_title. Acesso em: 08 maio 2020.

BORTONI-RICARDO, S. M. Educação em língua materna: a sociolinguística na sala de aula. São Paulo: Parábola Editorial, 2004

CONCEIÇÃO, R. B. da; PEREIRA, T. C. Avaliação de políticas que orientam o ensino da variação linguística. Web Revista SOCIODIALETO, v. 8, n. 23, p. 65-79, jun. 2018.

FARACO, C. A. Norma culta brasileira: desatando alguns nós. São Paulo: Parábola, 2008.

FREITAG, R. M. K. Entre a teoria e a prática: a Provinha Brasil e o tratamento da variação linguística na alfabetização. Interfaces cientificas-educaçâo, v. 3, n. 3, p. 43-54, 2015.

FREITAG, R. M. K. Sociolinguística no/do Brasil. Cadernos de Estudos Lingüísticos, v. 58, n. 3, p. 445-460, 2016.

LABOV, W. Language in the inner city: Studies in the Black English vernacular. University of Pennsylvania Press, 1972.

LUCCHESI, D. Ciência ou dogma? O caso do livro no MEC e o ensino de língua portuguesa no Brasil. Revista Letras, Curitiba, n. 83, p. 163-187, 2011.

LUCCHESI, D. Língua e sociedade partidas: a polarização sociolinguística do Brasil. São Paulo: Editora Contexto, 2015.

PAIVA, M. da C. de; SCHERRE, M. M. P. Retrospectiva sociolingüística: contribuições do PEUL. DELTA:

Documentação de Estudos em Lingüística Teórica e Aplicada, v. 15, n. SPE, p. 201-232, 1999.

SCHERRE, M. M. P. Padrões sociolinguísticos do português brasileiro: a importância da pesquisa variacionista. Tabuleiro de Letras, n. 4, 2012.

VIEIRA, S. R. Gramática, variação e ensino: diagnose e propostas pedagógicas. 2. ed. São Paulo: Blucher, 2018.

VIEIRA, S. R.; LIMA, M. D. A. de O. (Orgs.). Variação, gêneros textuais e ensino de Português: da norma culta à norma-padrão. Rio de Janeiro: Letras UFRJ, 2019.

ZILLES, A. M. S.; FARACO, C. A. (Org.). Pedagogia da variação linguística: língua, diversidade e ensino. São Paulo: Parábola Editorial, 2015. 